\title{
Influences of academic training and nonacademic experience on susceptibility to the horizontal-vertical illusion
}

\author{
KIMBERLY R. EDWARDS and GARY M. BROSVIC \\ Rider College, Lawrenceville, New Jersey \\ and \\ ROBERTA E. DIHOFF \\ Rowan College, Glassboro, New Jersey
}

\begin{abstract}
Subjects with varying levels of academic training and nonacademic experience adjusted the vertical lines of $L$-shaped and inverted-T figures and produced estimates of 1 -in. lines in the vertical and horizontal planes. The adjustments and productions of the subjects who were experienced in working with lines of varying sizes and orientations, independent of education, were more accurate than those of subjects lacking such experience. Specialized academic training and handson experience were found to compensate for the robust tendency to overestimate the length of vertical lines.
\end{abstract}

Performance on a number of visual illusions, most notably the Müller-Lyer (ML) and horizontal-vertical (HV) illusions, has been shown to be influenced by experimental and subject factors. The experimental factors shown to influence magnitude of illusion include figural variations (e.g., Coren \& Porac, 1984), the provision of verbal feedback (e.g., Brosvic \& Cohen, 1988; Brosvic et al., 1993), and duration of visual inspection (e.g., Coren \& Porac, 1984). The subject factors shown to influence magnitude of illusion include age (e.g., Fraisse \& Vautrey, 1956), sex (Fraisse \& Vautrey, 1956), and the level and discipline of academic degree (e.g., Becker, 1972; Fraisse \& Vautrey, 1956; McBride, Risser, \& Slotnick, 1987), although the influences of this latter variable-specialized academic training and experience-have not been robust.

Becker (1972) reported that students who were made aware of the HV illusion in a survey class some years prior to testing were less susceptible to the illusion than students who were enrolled in a similar class, but not yet made aware. Similarly, Fraisse and Vautrey (1956) reported that students of natural science were significantly less susceptible to the HV illusion than students of social science. In light of these reports, it was surprising that performance on adjustment and production task forms of the HV illusion did not differ between architecture students and those enrolled in social science courses (McBride et al., 1987). However, as mentioned by McBride et al., the architecture students had only completed an introductory

Preliminary results of this study were presented at the 1993 Annual Meeting of the Eastern Psychological Association. Address correspondence to G. M. Brosvic, Biopsychology Laboratory, Department of Psychology, Rider College, 2083 Lawrenceville Road, Lawrenceville, NJ 08648-3099. drawing course, and it is likely that more academic training and applied experience would be needed before reduced susceptibility would be observed.

In a test of this hypothesis, we predicted that individuals possessing such training and experience would be less susceptible to the HV illusion. Similarly, we also examined whether this training must be "academic," or if it is a shared behavior found in professions that involved working with lines of varying size and orientation but that do not, per se, mandate formal academic training.

\section{METHOD}

\begin{abstract}
Subjects
Three target groups were identified-subjects with formal academic training and experience (architecture, natural science, computer-assisted drawing/manufacturing [CAD/CAM], and art), subjects with experience but not academic training (barbers, auto body repair workers, and masonry workers), and subjects with a history of nontechnical academic training (e.g., the social sciences). The subjects in the first group reported 3 years of specialized course work and accompanying experiences. Those in the second group reported receipt of either a high school diploma or its equivalent and 3 years of related employment. The subjects in the third group, evaluated for control purposes, reported 3 years of nontechnical college-level course work, primarily in the social and behavioral sciences.
\end{abstract}

\section{Procedure}

Each subject completed at least 20 trials on production (drawing of 1 -in. vertical and horizontal lines) and adjustment task ( $L$-shaped and inverted-T figures) forms of the HV illusion. For the production tasks, they were provided with blank sheets of paper and instructed to draw their best estimates of 1 -in. horizontal or vertical lines in the center of the page. For the adjustment tasks, they were presented with sheets of paper on which either an L-shaped or an inverted-T figure was printed, as well as with a standard white index card with rounded corners. The subjects were instructed to move the card up and down the vertical line (38 $\mathrm{mm}$ in length) an equal number of times and to mark the point where the uncovered portion of the vertical line was equal in length to the hor- 
izontal comparison line ( $25.4 \mathrm{~mm}$ in length). The stimuli were presented in a counterbalanced order and the adjusted and created lines were measured to the nearest millimeter; a mean accuracy score was then calculated.

\section{RESULTS}

As seen in Figure 1, adjustments of the vertical line in the inverted-T figure made by control, CAD/CAM, and science subjects were significantly less accurate than those of the subjects in the other groups $(F=15.6, p<.05)$. The subjects in the control, CAD/CAM, and science groups were also less accurate than the other subjects on the first trial $(t>5.37, p<.05)$ and, by Trial 10 , magnitude of illusion for the architecture, art, auto body, barber, and masonry subjects did not differ from zero (all $t \mathrm{~s}<1.05$; all ps $>.05$ ). As seen in Figure 2, no between-group differences were observed for adjustments of the vertical line in the L-shaped figure $(F=1.28, p>$ $.05)$. In subsequent comparisons, the subjects in the control, CAD/CAM, and science groups were less accurate than the other subjects on the first trial $(t>3.24, p>$ $.05)$; however, no between-group differences were observed by Trial 8 and, by Trial 15 , magnitude of illusion

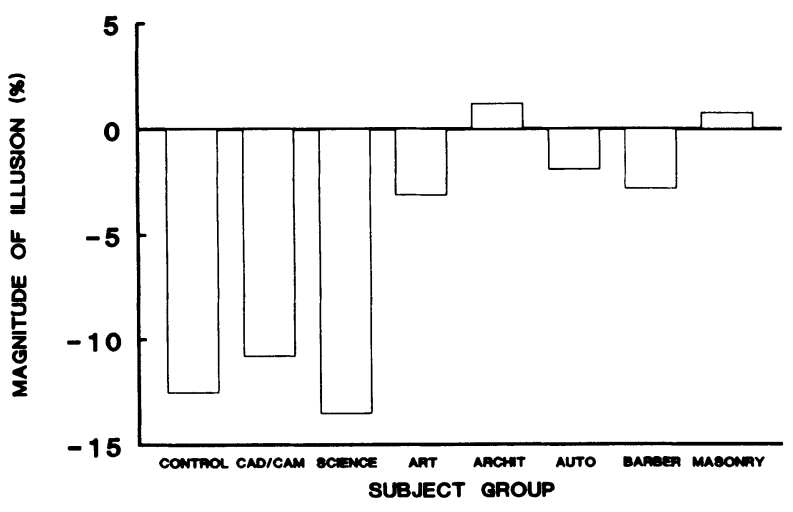

Figure 1. Magnitude of illusion for adjustments of inverted-T figures.

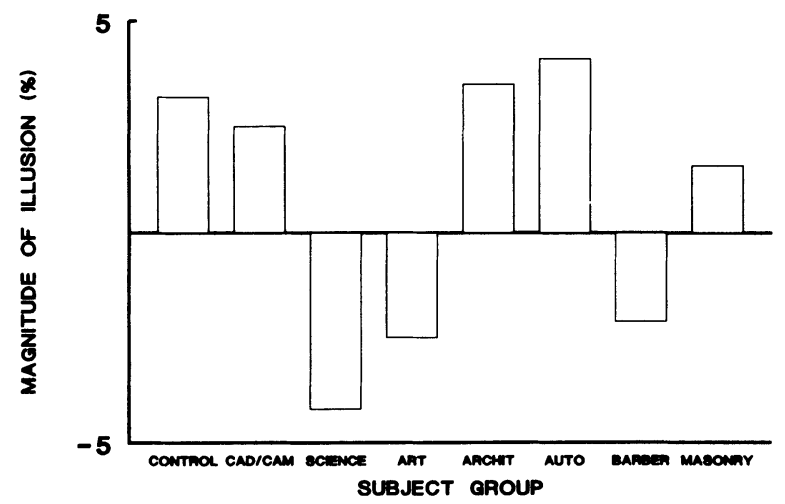

Figure 2. Magnitude of illusion for adjustments of $\mathbf{L}$-shaped figures.

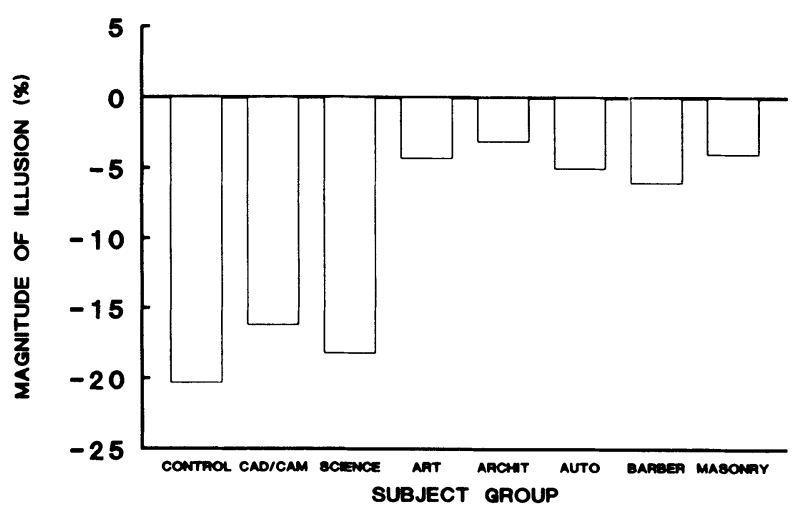

Figure 3. Magnitude of illusion for productions of 1-in. vertical lines.

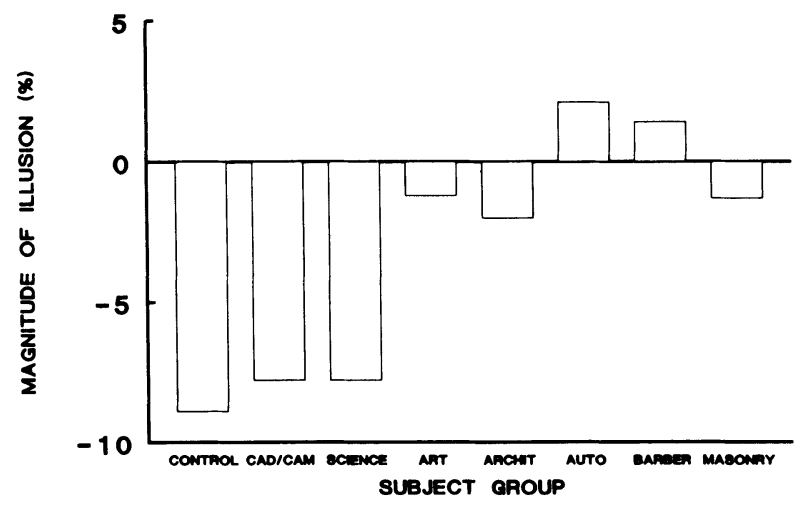

Figure 4. Magnitude of illusion for productions of 1-in. horizontal lines.

did not differ from zero for any group (all $t \mathrm{~s}<1.47$; all $p s>.05$ ).

As seen in Figure 3, the productions of 1 -in. vertical lines made by control, CAD/CAM, and science subjects were significantly less accurate than those of the other subjects $(F=32.46, p<.05)$. Similarly, as seen in Figure 4, productions of 1-in. horizontal lines made by control, CAD/CAM, and science subjects were also significantly less accurate than those of the other subjects $(F=$ $7.86, p<.05)$. In subsequent tests for both production tasks, control, CAD/CAM, and science subjects were less accurate than the other subjects on the first trial $(F>$ $4.51, p<.05$ ) and, by Trial 12 , magnitude of illusion for architecture, art, auto body, barber, and masonry subjects did not differ from zero (all $t \mathrm{~s}<.78$; all $p s>.05$ ).

\section{DISCUSSION}

Architecture, art, auto body, barber, and masonry subjects were consistently more accurate at drawing 1-in. horizontal and vertical lines and adjusting the vertical line of inverted-T figures than were control, $\mathrm{CAD} / \mathrm{CAM}$, and science subjects. It was surprising that reduced susceptibility was not also observed for the CAD/CAM group; however, a review of subject debriefings indicated a perceived lack of transfer between the authoring and editing of intersecting lines embedded within complex schematic drawings and the adjustment and production of iso- 
lated vertical and horizontal lines within the simple line drawings used in the present study.

These results represent the first substantial support for the hypothesis that specialized academic training systematically reduces susceptibility to the HV illusion. Similarly, the present results also represent the first substantial report of reduced susceptibility for some subjects lacking formal academic training but vocationally experienced in working with lines of varying sizes and orientations. The finding that magnitude of illusion for the HV illusion is influenced by experience per se is similar to Segall, Campbell, and Herskovits's (1966) report that dwellers of a restricted environ (equatorial forest) were less susceptible to a visual illusion than were dwellers of an urban environ, with an intermediate level of susceptibility observed for dwellers of the plains.

Although the present findings appear to be inconsistent with those of Becker (1972) and McBride et al. (1987), it is important to note that the subjects described in those studies reported considerably less specialized training and experience than those tested in the present study. The cumulative effects of specialized training and hands-on experience appear to compensate for the robust tendency to overestimate the length of vertical lines.

\section{REFERENCES}

Becker, J. A. (1972). Division and orientation in the vertical-horizontal illusion. Perceptual \& Motor Skills, 34, 899-902.
Brosvic, G. M., \& Cohen, B. (1988). The horizontal-vertical illusion and knowledge of results. Perceptual \& Motor Skills, 67, 463-469.

Brosvic, G. M., Farrelly, M., Risser, J. M., Shander, J., ClayTON, J., SYPEK, E., KAFER, L. B., \& Dihoff, R. E. (1993). MüllerLyer illusion and the structure-strategy dichotomy. Bulletin of the Psychonomic Society, 31, 11-12.

Coren, S., \& Porac, C. (1984). Structural and cognitive components in the Müller-Lyer illusion assessed via the cyclopean presentation. Perception \& Psychophysics, 35, 313-318.

Fraisse, P., \& Vautrey, P. (1956). The influence of age, sex, and specialized training on the vertical-horizontal illusion. Quarterly Journal of Experimental Psychology, 8, 114-120.

McBride, S. A., Risser, J. M., SLotnick, B. M. (1987). The horizontal-vertical illusion: Independence of line bisection and a comparison line. Perceptual \& Motor Skills, 64, 943-948.

Segall, M. H., Campbell, D. T., \& Herskovits, M. J. (1966). The influence of culture on visual perception. New York: Bobbs-Merill.

(Manuscript received May 17, 1993.) 